\title{
Investigation of Applicability of Additive Manufacturing Processes to Appropriate Technologies for Developing Countries
}

\author{
Dong-Gyu Ahn ${ }^{\dagger}$ \\ Department of Mechanical Engineering, Chosun University, 309 Pilmun-daero, Dong-gu, Gwang-ju 61452, Republic of Korea
}

\section{개발 도상국들을 위한 적층 제조 공정의 적정 기술 분야 적용성 고찰}

\author{
안동규 \\ 기계공학과, 조선대학교, 309 필문대로, 동구, 광주 61452 , 대한민국
}

\begin{abstract}
최근에 4차 산업 혁명을 견인하기 할 수 있는 다품종 소량을 위한 주요 제조 기술로써 적층 제조 공정이 부각 되고 있 다. 적층 제조 공정의 층별 적층 특성은 상대적으로 저비용으로 3차원 형상과 기능성을 가진 실제 제품을 쾌속 제작 할 수 있다. 이 논문의 목적은 개발 도상국들을 위한 적층 제조 공정의 적정 기술 분야 적용성에 대한 고찰이다. 적층 제조 공정의 적정 기술 적용 예들에 대한 조사/분석을 수행하여, 적층 제조 공정의 적정 기술 분야 실제 활용 가능성 에 대하여 고찰하였다. 또한, 적층 제조 공정의 적정 기술 분야에 대한 주요 적용 예들을 소개하였다. 최종적으로 개 발 도상국에서 적층 제조 기술을 이용한 실제적 제품 생산에 관련된 적정 기술 측면의 향후 발전 방향에 대하여 토론 하였다.

In recent years, additive manufacturing (AM) processes have emerged as an important manufacturing technology for a multi-item small sized production to lead the 4th industrial revolution. The layer-by-layer deposition characteristics of AM process can rapidly produce physical parts with three-dimensional geometry and desired functionality in a relatively low cost environment. The goal of this paper is to investigate the applicability of AM process to appropriate technologies for developing countries. Through the review of examples of appropriate technology of the AM process, the possibility of a practical usage of the AM process for the appropriate technologies is examined. In addition, significant applications of the AM process to the appropriate technology are introduced. Finally, future issues related to production of physical parts for developing countries using the AM process are discussed from the viewpoint of the appropriate technology.
\end{abstract}

KEYWORDS: Additive manufacturing, Applicability, Appropriate technology, Practical usage, Developing country, Future issues

서론

최근 스마트 공장 (Smart factroy) 의 핵심 기술중 하나로 적층 제조 (Additive manufacturing: $\mathrm{AM}$ ) 공정에 관한 관심 이 매우 높아지고 있다(Forcina et al., 2021). 적층 제조 공 정은 $3 \mathrm{D}$ 프린팅 공정이라고 불리기도 한다(Lee et al., 2020;

${ }^{\dagger}$ To whom correspondence should be addressed.

E-mail: smart@chosun.ac.kr

Received: 18 October 2021, Revised: 28 October 2021,

Accepted: 29 October 2021
Gwamuri et al., 2016). 적층 제조 공정의 원리는 Figure 1과 같다. 입체 형상 모델링으로 제작하고자 제품을 설계한 후, 제품의 표면만을 삼각형망으로 형성 시킨 STL 형식의 파일로 저장 한다(Ahn, 2016; Ahn, 2021). 이 데이터를 적 층 제조 공정에 특화된 적층 데이터 생성(CAM) 프로그램 에 입력하여 제품 위치, 적층 방향 및 지지대 생성을 수행 한 후, 각 적층 제조 공정에 적합한 적층 두께로 슬라이싱 (Slicing) 한다(Ahn, 2016; Ahn, 2021). 각 층에 대한 슬라이 싱 데이터를 이용하여 각층별 적층 경로를 생성한다(Ahn, 2016; Ahn, 2021). 각층별 적층 경로 데이터를 적층 제조 장 
치에 전송하면, 적층 제조 장치에서 재료를 한층씩 적층한 다(Ahn, 2016; Ahn, 2021). 이 과정을 반복하여 최종적으로 3 차원 형상을 가진 제품을 제작한다(Ahn, 2016; Ahn, 2021). 적층 제조 공정은 층별 적층 특성은 복잡한 형상을 가진 제 품과 기능성이 요구되는 제품을 금형/치구등을 제작할 필요 없이 $\mathrm{CAD} / \mathrm{CAM}$ 환경에서 빠른 시간내에 제작할 수 있는 장점을 가지고 있다(Ahn, 2016; Ahn, 2021).

1984년 미국의 Charles W. Hull 이 광조형(Stereolithography: $\mathrm{SL})$ 공정을 개발한 후, 다양한 적층 제조 공정들이 개발/상 용화 되었다(Lee et al., 2020; Gwamuri et al., 2016; Ahn 2016). ISO/ASTM 에서는 Figure 2와 같이 7가지로 적층 제 조 공정을 구분하고 있다(Ahn 2016; Ahn 2021; Pascal et al., 2021). 2006년부터 독일에서 시작된 RepRap 프로젝트가 시 작되는 시점부터 재료 압출(Material extrusion: $\mathrm{ME}$ ) 기반의 저가형 적층 제조 장치들이 출시되기 시작하면서, 적층 제 조 공정의 저변이 매우 확대되고 있다(Gwamuri et al., 2016; Pascal et al., 2021). 적층 제조 장치가 저가화 되고 오픈 소 스 기반의 적정 기술(Open source - appropriate technology: OSAT)이 개발됨으로써, 개발도상국에서도 적층 제조 공정 이 건축, 의료, 교육, 제조, 헬스케어 등에 다양하게 적용되 고 있다(Gwamuri et al, 2016; Ishengoma and Mtaho, 2014). 생활/의료/공업 제품 제조 시설이 부족한 개발도상국에서는 제품에 대한 제조 비용과 납기를 감소시키며 제품 품질을 어느 정도 보장할 수 있는 저가형 적층 제조 장치의 활용 이 두드러지게 증가하고 있다(Ishengoma and Mtaho, 2014; Ibrahim et al., 2015).

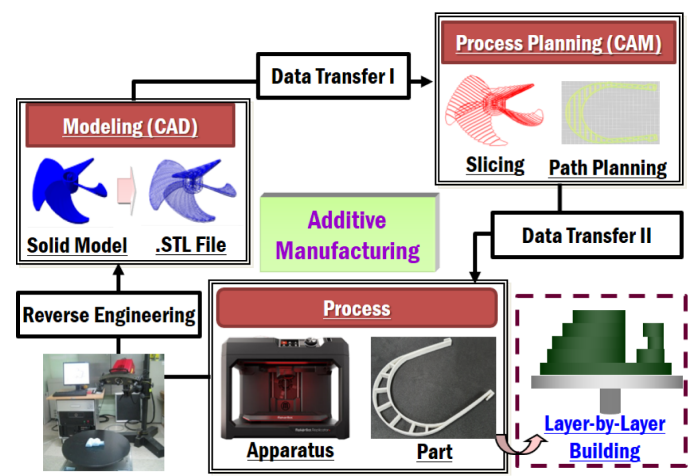

Figure 1. Principle of additive manufacturing process.

이 논문에서 개발도상국들을 위한 적층 제조 공정의 적 정 기술 분야 적용성에 대하여 분석/고찰하고자 한다. 적층 제조 공정의 적정 기술 적용 예들에 대한 조사/분석을 수행 하여, 적층 제조 공정의 적정 기술 분야 활용 가능성에 대 하여 고찰하고자 한다. 또한 개발도상국에서 적층 제조 기 술을 이용한 실제적 제품 생산에 관련된 적정 기술 측면의

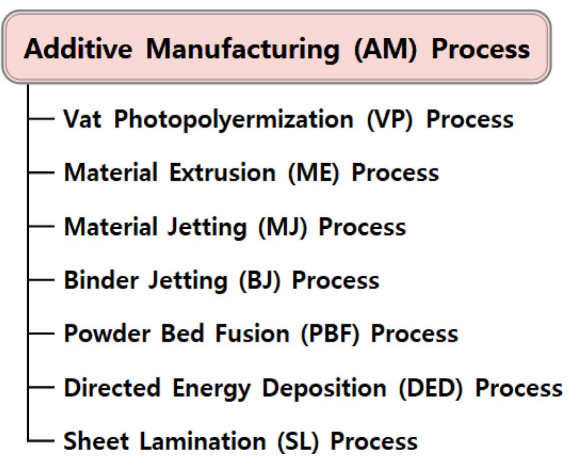

Figure 2. Classification of additive manufacturing process (Lee et al, 2020).

발전 방향에 대하여 토론하고자 한다.

\section{적정 기술을 위한 적층 제조 장비 개발/제작}

최근의 적층 제조 장치 관련 주요 사례들 중에서 적정 기 술 측면의 주목할 내용은 저가 적층 제조 장치 개발/제작 이 다. 저가의 적층 제조 장치 개발/제작 관련 주요 사례로는 Table 1 과 같이 전자 제품 폐기물을 이용한 저가의 적층 제 조 장치와 태양광 등 재생 에너지(Renewable energy)를 에 너지원으로 사용하는 적층 제조 장치 개발을 들 수 있다.

토고(Togo)의 WoeLab에서는 아프리카의 버려지는 엄청 난 량의 독성을 가진 전자제품 폐기물(Toxic e-waste)로부터 주요 부품을 재활용하여 $\mathrm{ME}$ 기반의 저가 적층 제조 장치 를 개발/ 제작하였다(Giles, 2018). 이러한 접근을 통하여 독 성을 가진 전자제품 폐기물들이 개발도상국내 버려지는 것 을 감소시키는 것과 동시에 전자 제품 부품/재료를 재활용 하여 개발도상국 국민들의 새로운 수입원도 창출할 수 있 었다. 또한 기술적 계몽을 실현하여 다수의 고용과 창업을 가능하게 하였다. 미시간 공과대학교의 Jashua Pearce 교수 등은 Figure 3 과 같은 태양광 패널이 부착되어 태양광으로 부터 장치 운영 에너지를 자체적으로 생산하는 적층 제조 장치를 개발하였다(Gwamuri et al., 2016; The Recycler,

Table 1. Examples of development and utilization of a low cost AM apparatus

\begin{tabular}{|c|l|c|}
\hline Type & \multicolumn{1}{|c|}{ Feature } & Ref. \\
\hline $\begin{array}{c}\text { Recycle of } \\
\text { toxic } \\
\text { e-waste }\end{array}$ & $\begin{array}{l}\cdot \text { Reduction of dangerous waste } \\
\cdot \begin{array}{l}\text { Providing new source of income } \\
\text { Realization of technological } \\
\text { enlightenment }\end{array}\end{array}$ & (Giles, 2018) \\
\hline $\begin{array}{c}\text { Usage of a } \\
\text { renewable } \\
\text { energy }\end{array}$ & $\begin{array}{l}\cdot \text { Utilization of solar energy } \\
\text { Solving energy problem in } \\
\text { developing countries }\end{array}$ & $\begin{array}{c}\text { (Gwamuri } \text { et al. } \\
\text { 2016; The Recy- } \\
\text { cler, 2015) }\end{array}$ \\
\hline
\end{tabular}




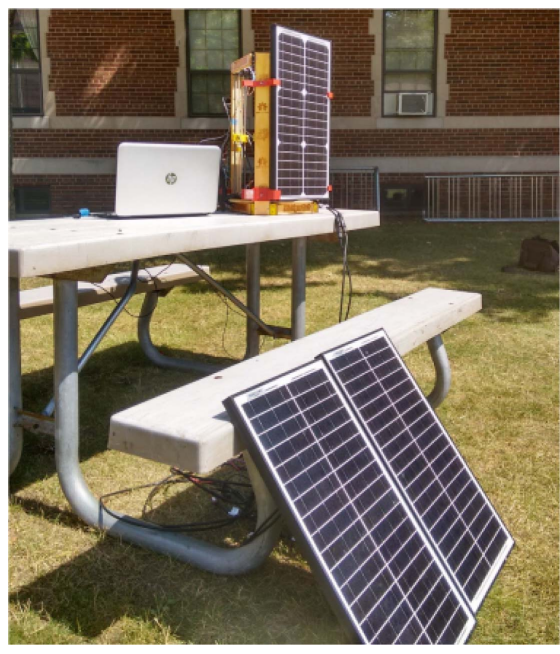

Figure 3. Additive manufacturing apparatus with solar panels (Adapted from figures of reference 3 (Open access)) (Gwamuri et al., 2016).

2015). 개발도상국에서 이 적층 제조 장치를 사용할 경우, 저개발 국가에서 항상 문제가 되고 있는 적층 제조 장치 운 영을 위해 소요되는 에너지 공급 문제를 해결할 수 있다.

Jashua Pearce 등에 의하여 오픈 소스와 RepRap 기반의 적 층 제조 장치를 이용하는 OSAT의 개발이 활발 진행되었다 (Gwamuri et al., 2016). 최근 아프리카(Africa)에서는 케냐 (Kenya)의 Start-up 기업인 AB3D 사를 시작으로 OSAT를 활 용한 저가 적층 제조 장치의 제작/판매 기업들이 증가하고 있다(Table 2, Schowtter and Van Wiele, 2018). AB3D 사에 서 개발한 적층 제조 장치는 약 USD 400 정도로 매우 저 가이다(Schowtter and Van Wiele, 2018). AB3D 사는 적층 제 조 장치의 제작 비용을 감소 시키기 위하여 대부분의 전기 /전자 부품/재료를 전기/전자제품 폐기물 센터로부터 수집 하여 재활용하였다(Schowtter and Van Wiele, 2018).

\section{적층 제조 기술을 이용한 사회적 기업 창업 및 제품 제조 지원}

Africa에서는 OSAT 기반의 저가 적층 제조 장치를 이용 한 사회적 기업/창업 프로그램이 다수 진행되고 있다 (Ishengoma and Mtaho, 2014; Schowtter and Van Wiele, 2018). Table 2는 OSAT 기반 적층 제조 장치를 활용하는 사 회적 기업 및 관련 프로젝트의 예이다(Schowtter and Van Wiele, 2018). AB3D 사에는 OSAT 기반 저가 적층 제조 장 치의 판매와 교육 도구 제작 지원을 수행하고 있다(Schowtter and Van Wiele, 2018). Artisan Hive 프로젝트는 2016년에 개
발도상국의 사회적 문제들을 해결하기 위하여 설립되었다 (Schowtter and Van Wiele, 2018). Artisan Hive는 지역 어부 들의 부족한 조명 문제를 해결하기 위해 저가 적층 제조장 치로 헤드램프를 제작하였다(Schowtter and Van Wiele, 2018). 그리고 향후 이 기술을 지역 어부들에게 교육 시킴 과 동시에 장비를 보급하여 헤드램프를 판매하여 새로운 수 익을 창출하게 할 계획을 수립하였다(Schowtter and Van Wiele, 2018). MedTech Kijenzi 프로젝트에서는 2014년부터 Kenya 시골 의료 시설에서 직면하고 있는 장비 공급부족의 완화를 목적으로 시작되었다(Schowtter and Van Wiele, 2018). MedTech Kijenzi 프로젝트에서는 적층 제조 기술을 교육 받 은 의료 종사자들이 현업에서 직접 적층 제조 장치로 의료 제품/장비를 제작하게 하는 것이다(Schowtter and Van Wiele, 2018).

Table 2. Social Entrepreneurs utilizing OSAT AM apparatus (Schowtter and Van Wiele, 2018)

\begin{tabular}{|c|c|c|}
\hline $\begin{array}{c}\text { Company/ } \\
\text { Program }\end{array}$ & Products & $\begin{array}{c}\text { AM } \\
\text { apparatus }\end{array}$ \\
\cline { 1 - 2 } AB3D & $\begin{array}{c}\text { Affordable apparatus } \\
\text { Education tool }\end{array}$ & \multirow{2}{*}{$\begin{array}{c}\text { RepRap } \\
\text { derivative }\end{array}$} \\
\cline { 1 - 2 } Happy Feet & Medicated shoes \\
\cline { 1 - 2 } Artisan Hive & Non limited scope & \\
\cline { 1 - 2 } MedTech Kijenzi & Medical equipment & \\
\hline
\end{tabular}

개발도상국은 통상적으로 전세계 제품 공급망에서 제외 되어 있다(Ishengoma and Mtaho, 2014). 그러나, 적층 제조 기술은 개발도상국들을 전세계 제품 공급망내에 포함 시킬 수 있게 한다(Ishengoma and Mtaho, 2014). 적층 제조 기술 을 활용할 경우 농경 제품, 제작 장비, 의료 장비/부품, 장 난감등 개발도상국 주민들이 필요한 제품을 자체적으로 제 작할 수 있다(Ishengoma and Mtaho, 2014). 이를 통하여 새 로운 직업과 경제적으로 윤택해 질 수 있게 한다(Ishengoma and Mtaho, 2014). 적층 제조 기술을 이용한 개발도상국 제 품 제조 지원에 관련된 대표적인 예로써는 남아프리카 지 역의 FabLab 프로그램을 들 수 있다(Ishengoma and Mtaho, 2014; Schowtter and Van Wiele, 2018). FabLab은 2005년도 에 시작하여 2017년부터 현재 남아프리카에 13개가 구축되 어 있으며, 케냐에는 FabLab 나이로비 (Nairobi) 외 1개의 FabLab이 운영되고 있다(Schowtter and Van Wiele, 2018). $\mathrm{FabLab}$ 에서는 주변 지역에서 요청되는 제품들을 제작하여 해당 지역에 공급함과 동시에 이와 관련된 창업과 일자리 창출도 함께 진행되고 있다. 


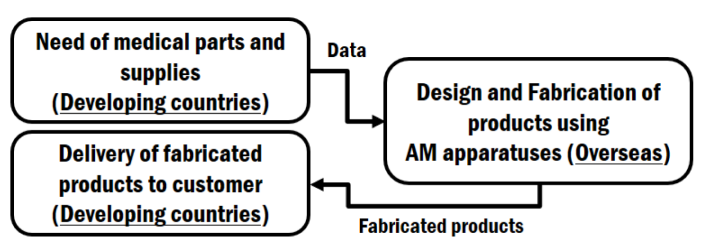

(a) without AM apparatus

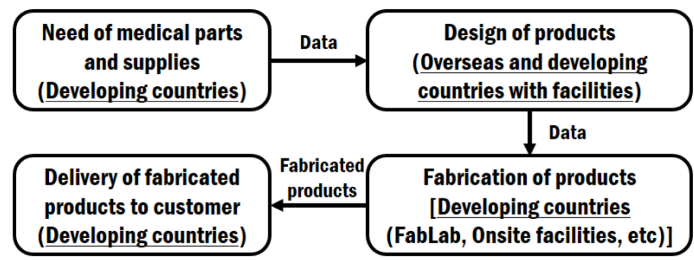

(b) with AM apparatus

Figure 4. Procedure for design and fabrication of medical products according to the facility possession of AM apparatus in developing countries.

\section{적층 제조 공정의 의료 분야 적용}

개발도상국을 위한 적층 제조 공정의 적정 기술 적용 분 야중 가장 두드러진 것이 의료 분야이다. 적층 제조 공정의 의료 분야 적용예는 기초 의료 장비/부품, 보철물, 접종 관 련 제품등 매우 다양하다(Ishengoma and Mtaho, 2014; Ibrahim et al., 2015; Schowtter and Van Wiele, 2018; Hwang and Ahn, 2021; Owen, 2015; McCracken, 2014). 개발도상국 을 위한 적층 제조 공정의 의료제품 제작/지원 개념은 Figure 4 와 같이 적층 제조 장치 및 관련 설비의 개발도상국내 구 축 여부에 따라 달라진다. 현재까지 개발도상국 의료분야에 적용된 예들은 거의 대부분 Figure 4(a)의 경우이며, 최근에 는 $\mathrm{FabLab}$ 등 개발도상국내에 적층 제조 장치와 관련 설계 시스템이 구축되면서 Figure 4(b) 개념의 의료 분야 적용이 증가하고 있다.

Table 3 은 적층 제조 기술의 개발도상국 의료 분야 적용 예들이다. 미국의 Ian McHale 는 해외에서 개발도상국으로 부목의 대량 공급을 위하여 1 개당 2 센트 비용으로 제작 가 능한 손가락 부목(Finger splint)을 개발하였다(Ibrahim et al., 2015). 아이티 (Haiti)의 iLab에서는 지역병원을 위한 탯줄 겸 자(Umbilical clamp), 손가락 부목 등의 기초 의료용품에 대 한 시제품을 적층 제조 장치로 제작하여 공급하였다(Ishengoma and Mtaho, 2014; Ibrahim et al., 2015). 케냐의 FabLab 에 서는 적층 제조 공정으로 제작된 유아용 정맥 탐지기 (Infant vein finder)를 개발하였다(Ishengoma and Mtaho, 2014).

케냐의 나이로비 대학의 학생인 Alois Mbutura는 Makerbot $3 \mathrm{D}$ 프린터를 이용하여 유아용 정맥 주사 바늘을 위한 도구 (Gadget)를 제작하였다(The Recycler, 2015). 트리니다드 토
Table 3. Medical applications of AM process for developing countries

\begin{tabular}{|c|c|c|c|}
\hline Application & Fabrication & $\begin{array}{l}\text { Applied } \\
\text { country }\end{array}$ & Ref. \\
\hline Finger splint & - & - & $\begin{array}{l}\text { (Ibrahim et al., } \\
\text { 2015) }\end{array}$ \\
\hline $\begin{array}{c}\text { Umbilical clamps for a } \\
\text { local hospital }\end{array}$ & \multirow{3}{*}{ iLab } & \multirow{3}{*}{ Haiti } & \multirow{3}{*}{$\begin{array}{l}\text { (Ishengoma and } \\
\text { Mtaho, 2014; } \\
\text { Ibrahim et al., } \\
\text { 2015) }\end{array}$} \\
\hline Finger splints & & & \\
\hline Casts & & & \\
\hline Infant vein finder & FabLab & \multirow{2}{*}{ Kenya } & $\begin{array}{l}\text { (Ishengoma and } \\
\text { Mtaho, 2014) }\end{array}$ \\
\hline $\begin{array}{c}\text { Gadget of intravenous } \\
\text { needles }\end{array}$ & $\begin{array}{l}\text { Uni. of } \\
\text { Nairobi }\end{array}$ & & $\begin{array}{l}\text { (The Recycler, } \\
\text { 2015) }\end{array}$ \\
\hline Anatomical model & $\begin{array}{c}\text { Univ. of } \\
\text { Trinidad and } \\
\text { Tobago }\end{array}$ & $\begin{array}{c}\text { Trinidad and } \\
\text { Tobago }\end{array}$ & $\begin{array}{l}\text { (Ishengoma and } \\
\text { Mtaho, 2014) }\end{array}$ \\
\hline 3D Printed Hands & $\begin{array}{c}\text { Not } \\
\text { Impossible } \\
\text { Lab. }\end{array}$ & Sudan & $\begin{array}{c}\text { (Ibrahim et al., } \\
\text { 2015; } \\
\text { McCracken, } \\
\text { 2014) }\end{array}$ \\
\hline 3D Printed Hands & $\begin{array}{l}\text { e-NABLE } \\
\text { community }\end{array}$ & Nigeria & (Owen, 2015) \\
\hline $\begin{array}{l}\text { Mould for prosthetic } \\
\text { linear }\end{array}$ & Create $O \& P$ & Nepal & (Saunders, 2019) \\
\hline Faceshield & $\begin{array}{l}\text { Addis Ababa } \\
\text { Univ. }\end{array}$ & Ethiopia & $\begin{array}{l}\text { (Kim et al., 2020; } \\
\text { 국민일보, 2020) }\end{array}$ \\
\hline Vaccine Carrier & \begin{tabular}{c|} 
Seoul \\
National Univ.
\end{tabular} & - & - \\
\hline
\end{tabular}

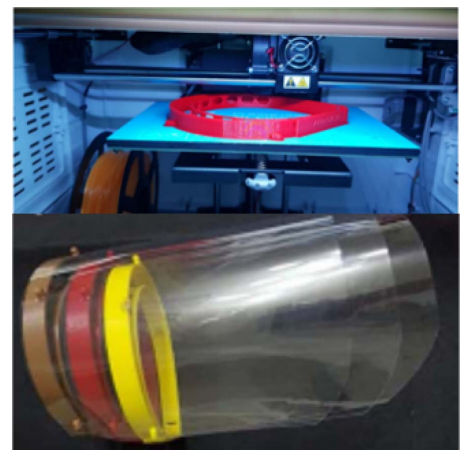

Figure 5. Protective faceshield fabricated by AM apparatus (adapted from figures of reference with permission) (Kim et al., 2020).

바고(Trinidad and Tobago) 대학에서는 적층 제조 장치로 해 부학 모델 (Anatomical model) 을 제작하여 수술자와 헬스케 어 기관이 활용할 수 있게 하였다(Ishengoma and Mtaho, 2014).

개발도상국에는 전쟁, 질병, 극도의 가난 및 테러리즘에 
의하여 손발을 잃은 장애인들이 매우 많다(Owen, 2015). 이 러한 장애인들에게 적층 제조 공정으로 제작된 저가의 인 공 팔다리(Limbs), 보철물(Prosthesis) 등을 제공하여 재활에 도움을 주고자 하는 시도들이 다양하게 이루어지고 있다. 미 국의 Not Impossible Lab은 손가락이 제어 가능한 저가의 인 공 팔을 적층 제조 장치로 제작하여 수단(Sudan)의 14세 어 린이에게 제공하고 실제 착용하여 생활하게 함으로써 어린 이의 일상 생활과 재활에 기여하였다(Ibrahim et al., 2015; McCracken, 2014). 이 Lab에서 적층 제조 장치로 인공 팔을 제작시, 제작 시간과 비용은 각각 6시간과 USD 100 정도 가 소요되었다(Ibrahim et al., 2015). e-NABLING 아프리카 에서는 적층 제조 장치로 움직일 수 있는 인공 팔을 제작 하여 나이지리아(Nigeria)의 12 세 어린이인 Musa 에게 제공 하였다(Owen, 2015). Musa 는 이 인공 팔을 실제 착용하여 생활을 하고 있다(Owen, 2015). 인공 팔을 제작하여 위하여 평균 12-20시간 정도가 소요되었다(Owen, 2015). USD30-50 이 요구되는 1 개의 공급재료 롤당 3-4개의 인공팔을 제작 할 수 있었다(Owen, 2015).

Creat O\&P 사는 네팔(Nepal)에서 지진에 의하여 손발을 잃은 장애인들이 보철물 부착시 기동성과 안락성을 향상 시 키기 위하여 손상된 손/발과 보철물 사이에 고분자 라이너 (Linear)를 제작/삽입하는 SILC(Slicone interface liner comfort) 프로젝트를 수행하였다(Saunders, 2019). SILC 프로젝트에 서는 적층 제조 장치로 $\mathrm{Gel}$ 형 라이너를 성형할 수 있는 성 형 몰드(Mold)를 개발하였다(Saunders, 2019). 이 성형 몰드 를 이용하여 실리콘으로 라이너를 제작하여 장애인의 손/발 과 보철물 사이에 실제로 삽입/적용하였다(Saunders, 2019). 이 라이너 제작 가격은 USD 50 이하로, 일반적으로 선진국 에서 실리콘 라이너 제작 비용이 USD 200 이상인 것과 비 교하여 현저히 저렴함 가격으로 개발도상국에 공급할 수 있 었다(Saunders, 2019).

에디오피아(Ethiopia)의 아디스 아바바(Addis Ababa) 대학 교의 김경만 교수님팀에서는 적층 제조 장치로 Figure 5와 같이 안면 보호구를 제작하여 에티오피아 딜라, 마다카스카 르 및 지부티의 지역 의료진들에게 전달하여, COVID-19 팬 더믹에 대응할 수 있도록 하였다(Kim et al., 2020; 국민일 보, 2020). 서울대학교에서는 COVID-19 백신을 안전하게 운반할 수 있는 백신 케리어(Vaccine carrier) 개발에 대한 연 구를 수행하고 있다.

\section{적층 제조 공정의 건축 분야 적용}

적층 제조 공정중 Contour crafting 공정은 컴퓨터로 제어 되는 크레인이나 갠터리(Gantry)로 콘크리트나 현지에서 공
급 가능한 건축 재료를 한층씩 적층하여 건물을 빠른 시간 내에 저렴하게 제작할 수 있다(Contour Crafting Corporation, 2017; Honrubia, 2018; Hossain et al., 2020; Pessoa et al., 2021). Contour crafting 공정은 2000년에 Univeristy of Southern California에서 개발되었으며, Figure 6과 같이 현재 사무실 빌딩, 다리, 조형물 등 다양한 건축 분야에 활용되고 있다 (Hossain et al., 2020; Pessoa et al., 2021).

최근에 Contour crafting 공정이 개발도상국의 주택, 도서 관, 학교등에 Table 4와 같이 활용되기 시작하고 있다(Fleming, 2021; Keendjel, 2021; Wood, 2020; Malone, 2021). Africa에 서는 매일 4만명 정도의 주민들이 도시로 이주하고 있다. 그 래서 대부분의 아프리카 지역들에서는 주택 위기가 발생하 고 있다(Fleming, 2021). 나이지리아의 경우 1,700 만 가구 가 부족한 것으로 예측되고 있다(Fleming, 2021). 이러한 문 제를 해결하기 위하여 Contour crafting 공정을 이용한 저가 주택(Affordable house) 건설에 대한 사업들이 진행되고 있 다(Fleming, 2021). 협력 벤처(Joint venture) 인 14Trees는 말 라위(Malawi)와 케냐에 Contour crafting 을 이용하여 저가 주택들을 건설하고 있다(Fleming, 2021; Keendjel, 2021). 14 Tree 는 Contour crafting을 이용하여 말라위의 수도 리롱 위 (Lilongwe)에 최초의 저가 주택을 건설하였다(Fleming, 2021; Keendjel, 2021; Wood, 2020). 이 주택 건설시 총 12 시간과 USD 10,000 의 제작 시간과 비용이 소요되었다 (Fleming, 2021; Keendjel, 2021). 그리고 신규 가옥 건설시 전통적인 건축 방법에 비하여 Contour crafting 공정을 이용 하는 것이 $\mathrm{CO}_{2}$ 방출량도 $70 \%$ 이상 감소하는 것을 알 수 있 었다(Fleming, 2021; Keendjel, 2021; Wood, 2020). Contour

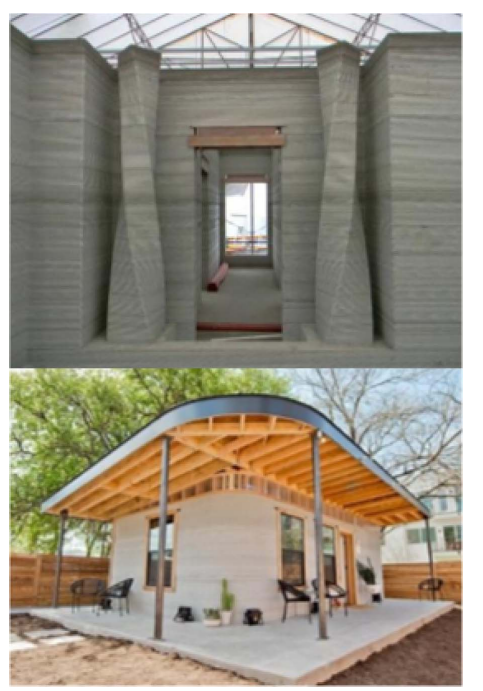

Figure 6. Applications of contour crafting process to building (Adapted from figures of reference 20 (Open access)) (Hossain et al., 2020). 
Table 4. Applications of contour crafting technology to developing countries

\begin{tabular}{|c|c|c|c|}
\hline \multicolumn{2}{|r|}{ Application } & $\begin{array}{l}\text { Applied } \\
\text { country }\end{array}$ & Ref. \\
\hline $\begin{array}{c}\text { Affordable } \\
\text { housing }\end{array}$ & $\begin{array}{l}\cdot \text { High speed of construction } \\
\text { (nearly } 12 \text { hours) } \\
\cdot \text { Cost of under USD } 10,000 \\
\cdot \text { Optimized material } \\
\cdot 70 \% \text { reduction of carbon } \\
\text { footprint }\end{array}$ & $\begin{array}{c}\text { Malawi, } \\
\text { Kenya }\end{array}$ & $\begin{array}{l}\text { (Fleming, } \\
\text { 2021; } \\
\text { Keendjel, } \\
\text { 2021; Wood, } \\
\text { 2020) }\end{array}$ \\
\hline \multirow{2}{*}{ School } & $\begin{array}{l}\cdot \text { World's } 1^{\text {st }} \text { school using AM } \\
\text { apparatus } \\
18 \text { hours for the } 600 \text {-sf wall } \\
\text { of school }\end{array}$ & Malawi & $\begin{array}{l}\text { (Fleming, } \\
\text { 2021; } \\
\text { Malone, } \\
\text { 2021) }\end{array}$ \\
\hline & $\begin{array}{l}\text { - Using concrete and locally- } \\
\text { sourced material } \\
\text { - Solar panel for power of } \\
\text { school }\end{array}$ & $\begin{array}{c}\text { Madaga- } \\
\text { scar }\end{array}$ & $\begin{array}{c}\text { (Carlson, } \\
\text { 2021) }\end{array}$ \\
\hline Toilet & $\begin{array}{l}\text { Research project } \\
\text { Special cements with the } \\
\text { recycled fly ash }\end{array}$ & India & (Richa, 2018) \\
\hline
\end{tabular}

crafting을 이용한 저가 주택 제작 방법은 급속하게 도시화 가 진행되는 아프리카 국가들의 주택 보급 위기를 극복할 주요 기술로 사료된다(Fleming, 2021).

14Tree는 말라위에 세계 최초로 Contour crafting 공정을 이용한 학교를 건설하였다(Fleming, 2021; Malone, 2021). 600 평방 피트(Square feet: SF)의 건물 벽을 18 시간에 제 작하였다. 학생들은 2021년 6월부터 학교에서 수업을 시작 하고 있다(Malone, 2021). 비영리 단체인 Thinking Huts 은 콘크리트와 지역 건축 재료를 사용하여 Contour crafting 공 정으로 교실, 과학실, 댄스 스튜디오가 포함된 학교인 Studio Maortazavi를 마다가스카르 (Madagascar) 의 피아나란쵸아 (Fianarantsoa)에 건설하였다(Carlson, 2021). 지붕에는 태양 광 패널(Solar panel)을 설치하여 학교에 필요한 전력을 공 급할 수 있게 하였다(Carlson, 2021). 인도(India)에서는 인도 의 매우 열악한 위생 환경을 해결하기 위하여 Contour crafting 공정을 이용한 화장실 건축에 대한 프로젝트를 싱 가폴과 협력하여 진행하고 있다(Richa, 2018). 이 프로젝트 에서는 재활용된 플라이 에쉬(Fly ash)를 혼합한 특수 시멘 트를 적층재료로 사용하고 있다(Richa, 2018).

\section{적층 제조 공정의 기타 적용 사례}

의료 및 건축 분야외에도 적층 제조 공정이 과학/기술 교 육 및 모형(Pattern), 농기구, 물 운반, 신발 제작등에 다양하 게 적용되고 있다(Ishengoma and Mtaho, 2014; Ibrahim et al., 2015; Inoma et al., 2020; TheCivilEngineer.org, 2018; Exploring the potential of 3D printing for agriculture, 2017). 나이지리아에서등에서 학생들 기술/과학 교육과 실험을 위 해서 정부적 차원에서 적층 제조 기술을 활용하고 있다 (Inoma et al., 2020). 나이지리아의 Nigerian Foundaries Ltd. 사에서는 주조 패턴 제작시 적층 제조 공정을 활용하고 있 다(Inoma et al., 2020). 나이지리아 의 창업 기업인 Elephab 는 자동차용 대체 부품을 적층 제조 공정으로 제작하고 있 다(Inoma et al., 2020). Jose Paris는 개발도상국 주민들이 대 량의 물을 손쉽게 운반하게 하기 위하여 적층 제조 공정으 로 부품이 제작된 태양광 충전형 물 운반 카트(Solar powered cart for water collection)을 설계/개발하였다(TheCivilEngineer.org, 2018). 이 물 운반 카트를 이용하여 케냐에서 물 운반 실험 을 진행할 예정이다(TheCivilEngineer.org, 2018).

아일랜드 대학 연구소로부터 시작된 $3 \mathrm{D} 4 \mathrm{AgDev}$ 프로젝트 에서는 말라위에서 지역 기능공 및 농부들의 협력으로 노 동력을 감소시킬 수 있는 농기구 시제품을 제작하였다 (Exploring the potential of 3D printing for agriculture, 2017). 이 프로젝트에서는 적층 제조 장치로 발효 시스템(Sparkling system)을 제작하였다(Exploring the potential of 3D printing for agriculture, 2017). 케냐의 나이로비 대학에서는 케냐 국 민들에게서 많이 발생하는 Jigger 벼룩감염증 문제를 해결 하기 위하여 적층 제조 장치로 플라스틱 신발(Shoes)를 제 작하였다(Ibrahim et al., 2015; Goehrke, 2014). Jigger 벼룩 증 Jigger 라는 모래 벼룩에 의하여 발이 감염되어, 발에 염 증이나 변형이 발생하는 것이다(Ibrahim et al., 2015; Goehrke, 2014). 케냐의 AB3D 사에서도 Jigger 벼룩 감염증을 예방 하기 위한 저가 신발을 OSAT 기반의 저가 적층 장치로 제 작하여 국민들에게 제공하고 있다(Schowtter and Van Wiele, 2018). 이 신발은 재사용된 플라스틱을 재료로 사용하였으 며, 신발을 완전히 마모된 후에 다시 재료로 재활용될 수 있 다(Ibrahim et al., 2015; Goehrke, 2014).

\section{결론 및 발전 방향}

이 연구에서는 개발도상국들을 위한 적층 제조 공정의 적 정 기술 측면 적용성을 실제 적용 사례 중심으로 분석/고찰 하여 다음과 같은 결론과 발전 방향을 도출할 수 있었다.

첫째, OSAT 기반 재활용 재료 및 신재생 에너지 이용 저 가 적층 제조장치의 개발과 활용이 개발도상국에서는 활발 히 이루어지고 있는 것을 알 수 있었다. 이를 통하여 폐기 물 감소, 운영 에너지 문제 해결, 창업을 통한 인력 고용 및 새로운 수입원 창출, 기술적 계몽등을 실현하고 있음을 알 수 있었다. 또한 FabLab 등을 통하여 적층 제조 공정을 이 
용한 개발도상국내 소요 제품들에 제작 지원도 이루어지고 있는 것을 알 수 있었다. 이 결과들로부터 향후 개발도상국 에서는 재활용 재료 및 신재생 에너지 활용 OSAT 기반 저 가 적층 제조 장치 개발과 이를 이용한 창업 및 제작지원 이 계속적으로 진행될 것으로 사료된다.

둘째, 적층 제조 공정이 개발도상국들의 의료 및 건축 분 야에 널리 적용되고 있음을 알 수 있었다. 의료분야에서는 의료 부품, 인공 팔/다리, 보철물, 보철물 제작 몰드, 개인용 보호 용품(Personnel protective equipment: PPE), 백신 케리 어등에 활용되고 있는 것을 알 수 있었다. 개발도상국의 주 택/학교 부족 문제를 해결하기 위하여 Contour crafting 공 정을 활용한 건축물 건설이 활발히 진행되고 있음을 알 수 있었다. 또한 개발도상국의 위생문제 해결을 위한 위생 시 설 건설에도 적층 제조 공정이 활용되고 있음을 알 수 있 었다. Contour crafting 공정을 사용할 경우 건축에 소요되 는 이산화탄소 발생과 저비용으로 빠른 시간내에 건물을 건 설할 수 있어, 향후 아프리카 지역의 도심화, 보건 환경 개 선 및 학교 건설에 이 공정의 활용도가 높을 것으로 사료 된다.

셋째, 적층 제조 공정이 개발도상국의 과학/기술 교육, 산 업 부품 제작, 저가 신발 제작등 다양한 분야에 활용되고 있 음을 알 수 있었다. 개발도상국의 기술 교육 활성화를 위하 여 적층 제조 공정과 이와 관련된 제품 설계 교육이 활성 화 될 것으로 전망된다. 농기구, 주물용 패턴 및 운송장치 대체 부품 제작등에도 적층 제조 장치의 활용이 높아질 것 으로 사료된다. 또한, 개발도상국의 질병 방지 제품과 자연 재해 발생시 필요한 구호 제품 및 피난처 등의 제작에 적 층 제조 공정이 폭넓게 사용될 것으로 사료된다.

적층 제조 기술이 개발도상국의 사회적 기업 창업, 새로 운 일자리 창출 및 기술적 계몽에 크게 기여할 것으로 사 료된다. 개발도상국의 국민들을 위한 의료 문제 해결과 주 택/교육 문제 해결에도 중요한 기술적 열쇠를 제공할 것으 로 판단된다. 또한, 개발도상국내 제조 기술이 지원되지 않 는 낙후 지역의 신속한 생활 제품 제조 지원과 삶의 질 개 선에 기여할 수 있을 것으로 사료 된다. 향후, 추가적인 연 구를 통하여 적정 기술 측면에서 적층 제조 기술과 기존 상 용 기술을 비교하여 기능성, 경제성, 사용성 등의 측면에서 비교/평가하여 개발도상국 적용 방향을 수립할 예정이다.

\section{References}

Ahn, D.-G. (2016). Direct Metal Additive Manufacturing Processes and Their Sustainable Applications for Green Technology: A Review, International Journal of Precision Engineering and Manufacturing-Green Technology, 3(4), pp. 381-395.

Ahn, D.-G. (2021). Directed Energy Deposition (DED) Process: State of the Art, International Journal of Precision Engineering and Manufacturing-Green Technology, 8(2), pp. 703-742.

Carlson, C. (2021). Studio Mortazavi to Build World's First 3Dprinted School in Madagascar, https://www.dezeen.com/2021/ 02/24/studio-mortazavi-worlds-first-3d-printed-school-madagascar (accessed 17 October 2021).

Contour Crafting Corporation (2017). https://www.contourcrafting.com/building-construction (accessed 17 October 2021).

Exploring the potential of 3D printing for agriculture, (2017) https:/www.thecivilengineer.org/news-center/latest-news/ item/1549-a-solar-powered-3d-printed-cart-could-revolutionize-water-collection-in-developing-countries (accessed 18 October 2021). (accessed 18 October 2021).

Fleming, S. (2021). The Affordable 3D-Printed Home that Could Transform Africa Urbanization, https://www.weforum.org/ agenda/2021/06/3d-printed-home-african-urbanization (accessed 17 October 2021).

Forcina, A., Introna, V. and Silverstri, A. (2021). Enabling Technology for Maintenance in a Smart Factory: A Literature Review, Procedia Computer Science, 180, pp. 430-435.

Giles, C. (2018). How a West African Lab Made a 3D Printer from Toxic e-waste, https://edition.cnn.com/2017/11/28/africa/3dprinter-electronic-waste/index.html (accessed 14 October 2021).

Goehrke, S. A. (2014). Engineering Students Design "Happy Feet," 3D Printed Shoes for Kenyans Afflicted by Jigger Infection, https://3dprint.com/25587/happy-feet-3d-printedshoes (accessed 18 October 2021). (accessed 18 October 2021).

Gwamuri, J., Franco, D., Khan, K. Y., Gauchia, L., and Pearce, J. M. (2016). High-Efficiency Solar-Powered 3-D Printers for Sustainable Development, Machines, 4(1), pp. 3. doi.org/ 10.3390/machines4010003

Honrubia, M (2018). 3D Printing and Its Application in the Construction Industry, https://www.ennomotive.com/3d-printingand-its-application-in-the-construction-industry (accessed 17 October 2021).

Hossain, M. A., Zhumabekova, A., Paul, S. C., and Kim, J. R. (2020). A Review of 3D Printing in Construction and Its Impact on the Labor Market, Sustainablity, 12(20), pp. 8492. doi.org/10.3390/su12208492

Hwang, A.-J. and Ahn, D.-G. (2021). A Study on Development of a Reusable Protective Face Shield Using a Material Extrusion Process, Journal of Korean Society of Precision Engineering, 38(7), pp. 549-556. 
Ibrahim, A. M. S., Jose, R. R., Rabie, A. N., Cerstle, T. L., Lee, B. T., and Lin, S. J. (2015). Three-dimensional Printing in Developing Countries, Plastic and Reconstructive Surgery-Global Open, 3(7), pp. e443. doi: 10.1097/GOX.0000000000000298

Inoma, A. O., Ibhadode, O. O. and Ibhadode, A. A. (2020). The Perception and Deployment of 3D Printing in the Nigerian Educational Sector for Science and Engineering Programs, 10, pp.e00641. oi.org/10.1016/j.sciaf.2020.e00641

Ishengoma, F. R. and Mtaho, A. B. (2014). 3D Printing: Developing Countries Perspectives, International Journal of Computer Applications, 104(1), pp. 30-34.

Keendjel, J. (2021). Africa's First 3d Printed Home Built in Just 12 Hours, https://www.techgazi.com/africas-first-3d-printedhome-built-in-just-12-hours. (accessed 17 October 2021).

Kim, G.-M., Assefa, D., Kang, J. W., and Gebreyouhannes, E. (2020). 3D-printed Face Shields for Healthcare Professionals Battling COVID-19 Pandemic, Journal of Appropriate Technology, 6(2), pp. 226-237.

Lee, I. H., Kim, H.-C. and Ahn, D.-G. (2020). Korean Terminologies for Additive Manufacturing According to the ISO/ ASTM 52900 Standard, Journal of Korean Society of Precision Engineering, 37(12), pp. 929-936.

Malone, D. (2021). The World's First 3D Printed School Completes in Malawi, Africa, https://www.bdcnetwork.com/ worlds-first-3d-printed-school-completes-malawi-africa (accessed 17 October 2021).

McCracken, H. (2014). How a TIME Article Led to the Invention of a $\$ 100$ 3D-Printed Aritifical Limb, https://techland.time.com/2014/01/07/how-a-time-article-led-to-theinvention-of-a-100-3d-printed-artificial-limb (accessed 16 October 2021).

Owen, J. (2015). e-NABLING Africa-3D Printed Hands In Nigeria, http://enablingthefuture.org/2015/10/24/e-nabling-africa$\%$ E2\%80\%A2-3d-printed-hands-in-nigeria (accessed 16 October 2021).

Pascal, S., Stefan, Z. and Kilian, G. (2021). Additive Manufacturing Research Landscape: A Literature Review, Proceedings of the 23th International Conference on Engineering Design
(ICED21), The Design Society, pp. 333-344.

Pessoa, S., Guimarães, A. S., Lucas, S. S., and Simões, N. (2021). 3D Printing in the Construction Industry - A Systematic Review of the Thermal Performance in Buildings, Renewable and Sustainable Energy Reviews, 141, pp. 110794. doi.org/ 10.1016/j.rser.2021.110794

Richa (2018). This is the World's First 3D Printed Toilet Made Specially for India!, https://www.geeetech.com/blog/2018/01/ this-is-the-worlds-first-3d-printed-toilet-made-specially-forindia (accessed 17 October 2021).

Saunders, S. (2019). Operation Namaste Making 3D Printed Molds for Prosthetic Aligners in Nepal, https://3dprint.com/ 261296/operation-namaste-3d-printing-molds-for-prostheticaligners-in-nepal (accessed 16 October 2021).

Schowtter, T. and Van Wiele, B. (2018). 3D Printing: Enabler of Social Entrepreneurship in Africa? - The Roles of FabLabs and Low-Cost 3D Printers, https://openair.africa/wp-content/ uploads/2020/05/WP-18-3D-Printing-Enabler-of-SocialEntrepreneurship-in-Africa.pdf(accessed 16 October 2021).

The Recycler (2015). Solar-powered 3D printers help developing countries, https://www.therecycler.com/posts/solar-powered3d-printers-help-developing-countries/(accessed 15 October 2021).

TheCivilEngineer.org (2018). A Solar-powered, 3D Printed Cart Could Revolutionize Water Collection in Developing Countries, https://www.thecivilengineer.org/news-center/latestnews/item/1549-a-solar-powered-3d-printed-cart-could-revolutionize-water-collection-in-developing-countries (accessed 18 October 2021).

Wood, G. (2020). LafargeHolcim Uses 3D Printing to Create Affordable Housing in Africa, https://www.forconstructionpros.com/concrete/news/21207921/lafargeholcim-northamerica-inc-lafargeholcim-uses-3d-printing-to-create-affordable-housing-in-africa. (accessed 17 October 2021).

국민일보 (2020). 얼굴가림막, 3D 프린터로 만들었다... 코로나 19 취약국가 아프리카 전달, http://m.kmib.co.kr/ view.asp?arcid=00146123541 (accessed 16 October 2021). 